\title{
Gender and Development: Looking Back, Looking Forward ${ }^{1}$
}

Wendy Harcourt

Email: harcourt@iss.nl

\section{Wendy Harcourt}

Affiliation: International Institute of Social Studies of Erasmus University Rotterdam City and country: The Hague, The Netherlands

Wendy Harcourt is Professor of Gender, Diversity and Sustainable Development and Westerdijk Professor at the International Institute of Social Studies of the Erasmus University Rotterdam. She is Chair of the ISS Institute Council as well as Coordinator of the EU H2020-MSCA-ITN-2017 Marie Sklodowska-Curie Innovative Training Networks (ITN) WEGO (Well-being, Ecology, Gender, and Community).

Running Header: Gender and development

Abstract: As editor of the Development journal for 23 years Wendy Harcourt takes a walk down memory lane in order to review the main themes that stand out for her as we consider what lies ahead. She reflects on four major themes which she argues informs development's past and future: diversity; body politics; post-development and sustainable development.

Keywords: diversity; body politics; post-development and sustainable development.

\section{Introduction}

Since its earliest days, the Development journal has signposted many if not all the trends in the practice and thinking about gender in development. Leading gender and development scholars and policy makers at the global level have published in its pages - from heads of UN agencies such as Nafis Sadik, Lourdes Arizpe and Noeleen Heyzer to global feminist advocates such as Gita Sen, Peggy Antrobus, Gigi Francisco, Jacqueline Pitanguy and Khawar Mumtaz. Development has hosted the new thinking of renown gender and development scholars such as Sylvia Tamale, Andrea Cornwall, Naila Kabeer, Vandana Shiva, Caren Grown and J.K. Gibson-Graham. And there have been a host of articles by a myriad of people who have shaped the gender debate at the local and regional level exploring concerns from economic empowerment, reproductive justice, women's rights as human rights and environmental feminism. As editor of the Development journal for 23 years I had the great pleasure and privilege of engaging and learning with these women, and some men, and later also transgender people on the importance of gender theory and practice in development. I devoted many an editorial and journal issue to gender themes.

\footnotetext{
1 This article is partially based on chapter 'Gender perspectives on development studies' written for a forthcoming book to be published by Palgrave - Building development studies for the new millennium edited by I.S.A. Baud, E. Basile and T. Kontinen.
} 
The article is reflection of the 'doing' of gender and development - as an editor, researcher and writer, as an advocate and as someone who, as a member of the SID network, was able to have access to change turning global conferences as well as cross the border into academic and social movement debates. My knowledge of gender and development is strongly marked by being part of the action, which allowed me to learn by observing how practitioners and advocates engaged and shaped development processes as they worked for gender justice in different development policy arenas. Now, as an academic, I have observed how scholars are also influenced by the development processes and networks in which they engage. There is no pure scholarly debate about gender and development. I also recognize how important the facilitating work of SID and its journal has been, and will continue to be, in the pursuit of transnational solidarity and alliances forged in efforts to ensure that gender is part of development processes.

In this article then, I am interested not so much in gender and development as a professional study of different development interventions to counter gender bias or gender inequality. I am more interested in how gender in development has been done, and to reflect on the experiences of people who are the subjects of development processes, including the development practitioners and scholars whose careers have been forged by engaging in development. In other words how gender and development is marked by both personal as well as the political engagement in development as a field for transformation.

\section{What is Gender?}

As many articles published in the Development journal show ${ }^{2}$, gender is not about adding in women, or studying gender as separate to other development processes. Gender operates at every level of human experience, from economic arrangements, culture and the state to interpersonal relationships and intimate emotions. This does not mean gender is experienced in the same way for every person. Gender is lived differently in diverse places, bodies and locations. Gender and development, then looks at how gender relations occur on a local to a world scale, even if not always in the same direction or at the same speed, as local gender relations interact with the global arena.

Paying attention to gender illuminates how economic and social development is determined by power relations among men and women and other genders. It reveals how systematic, unfavourable treatment of individuals on the basis of their gender denies them rights, opportunities and resources. Gender and development policies aim to redress these gender imbalances and biases through a redistribution of power and resources and a transformation of gender power relations at both local and global levels and in a variety of locations. In addition, looking at gender in

\footnotetext{
${ }^{2}$ See for example: Grown (2005); Barton (2006); Tamale (2009); Nayar (2009); Lind (2010); Cornwall and Akua Anyidoho (2011); Harcourt (2011); Belausteguigoitia Rius (2012); Sen (2013); Wichterich (2014).
} 
development challenges us to engage with culturally embedded normative beliefs. For example, the gendered assumptions that women are 'naturally' different from men that inform development texts, projects and policies, or the gender biases that inform daily interactions among development actors, including those that equate women with gender in development policy.

Following this line, understanding gender helps to break down the various assumptions around where gender power relations are happening. Gender is experienced in 'First World' and 'Third World'; 'Global North' and 'Global South' though it has different and complex ramifications in different contexts. The boundaries between geographic divides are also changing and along with it gender roles as more people are connected, virtually, or migrating or travelling for work or pleasure or are forced to move to other world regions. Looking at the way development operates aware of gender power relations, we can see how gender operates structurally and institutionally as well as in everyday life.

\section{Some Trends in Gender and Development}

\section{Gender and Diversity}

As mentioned at the outset there have been many debates informing gender and development that have been introduced by women's movement as well as women working in development policy. SID led that debate with the early SID-WID groups of the 1970s and with the support of groups such as Development Alternatives with Women for a New Era (DAWN) many of whose leaders have been on the SID Governing Council and Development Editorial Board.

But there have been many shifts in the understand of gender in development, characterized by the move from women in development 'WID' (1970s/1980s) to women and development 'WAD' to women and environment 'WED' (1989s/90s) to gender and development. 'GAD' (1990s/2000s). The interrogations of gender as a category has been consistent since those first days when development was about ensuring women were included in development processes (women in development). Since the late 1990s GAD was established as the approach - choosing gender over women, because it was recognized, particularly by women of colour and feminists from the Global South that there were differences within the category of 'woman' and 'man' (and other genders). In other words, it matters not only what gender you identify with, but also what class, race and religion you belong to, and how they intersect structurally and relationally. Diversity within gender acknowledges everyday realities where gender is one determinant of power relations. In order to understand gender, it is important to understand socialized sexual difference in a historically grounded manner in ways that able policy to tackle the racialized, heterosexual social order that informs dominant development discourse. This requires that we consider the intersections of race, gender and class (and other physical, social, economic and cultural divisions) which determine if individuals can access social and economic resources, exercise their reproductive rights, and how they can engage in political and cultural change processes. 
The term intersectionality which emerged in the late 1990s/2000s crossing over from academe into social movements, helps us to look at the 'intersections' of gender along with the systemic impact of other social categories. Accounting for both gender and diversity allows us to confront inequalities that structure the relative positions of women and men and other genders in development analysis and practice and to improve development outcomes for marginal groups in education, health and labour policy.

As we look to the future, we need to continue to look at how gender and diversity plays out in all development processes, in order to go beyond (sometimes unconscious) prejudice and assumption about others and the stereotypes which flatten other peoples' lives, rob people of dignity and the possibility of equal humanity and try to overcome the latent racism in development processes.

\section{Body Politics}

Another area to which I have personally paid a lot of attention in relation to advocacy in gender and development in the health and reproductive rights arena is the embodied experience of development or body politics. Body politics is about the political struggle of people to claim control over their own biological, social and cultural 'bodily' experiences. In development processes, body politics has been at the core of political struggles around gender equality, human rights and public health. The 1990s series of United Nations conferences consolidated gender and development practices around body politics as issues such as domestic violence, rape as a weapon of war; denial of sexual and reproductive rights; sexual oppression of women, children, homosexuals and transgender people; racism and ageism were put on the agenda. Body politics in the UN arena, for example, has successfully led to changing human rights and public health policy to include an awareness of bodily integrity and the right to sexual and reproductive healthcare services. The discussion of heteronormativity which questions heteosexuality as the only 'natural' order of things has opened up the possibility to discuss homosexuality, third sex and transgender as part of human rights, enabling the inclusion of people who had been silenced or excluded from development studies and practice.

Body politics literature has helped development to understand how issues around embodiment such as reproductive health, sexual rights, disabilities are important elements of the global human rights agenda. Body politics shows how sexuality is cannot be ignored, it is about power, and also about rights to bodily security, to reproductive and sexual rights. It positions sexuality as not only a problem related to risky behaviour, violations or violence but also as part of living well, equality and care and respect for others. Such an agenda is important to safe guard today because of the rise of fundamentalist factions - from the conservative right in the US to the extremist patriarchal regimes of ISIS - as well as the powerful and misogynist global sex industry. In the future we need to continue to address concerns around body politics to ensure reproductive choice, dignity for all bodies in their diversity, 
and rights to sexual expression without labelling non-heteronormative behaviour as deviant.

As I was writing this article I had the chance to meet up with Jacqueline Pitanguy, a feminist and Brazilian human rights activist, former member of the Editorial board of Development and for two terms Vice President of SID. We strolled the streets of Rome, as we reflected on our engagement in body politics and more broadly our contributions to gender and development. We have known each other for 27 years meeting just before (and then often during) the big UN Conferences in the 1990s. We agreed that much had been achieved, but much is under threat. She related how she continues to work in the small NGO she founded, CEPIA. She spoke with a deep sadness about the reversal of national development policies which had helped the poorest and most marginal women in Brazil. In her home town of Rio de Janeiro the gun wars, corruption and killings are preventing talented young people from moving the progressive agenda forward, though she feels that it is with the women and men who are rising from the Barrios that vision and hope remain.

\section{Post-Development}

The search for alternatives to development is another area that has been discussed in the pages of the journal and continues to inform critical gender and development theory and practice. Post-development queries the metaphors, ideologies and premises of development which perpetuate injustices and inequalities. An earlier editor of the Development journal, Wolfgang Sachs, argued in the journal pages that technocratic processes of development have silenced other cultures and peoples' ways of living. A long-time member of the editorial board, Arturo Escobar in his ground-breaking work, including in his articles published in Development, sees postdevelopment as forging new narratives, new ways of thinking and doing that are critical for both human and non-human living worlds. In an important journal issue in the early 2000s I co-edited with the late Smitu Kothari, many post-development writers set out the violence of development for communities around the world, making visible the way development projects would discriminate against peoples on the basis of gender, ethnicity, race and class. At the core of post-development is the call for a new way of understanding how to live within the limitations of Earth resources and to learn from and respect non-Western histories and cultures in the development processes.

In looking for a different set of ethics and values which promote life-affirming experiences and knowledge post-development learns from people living on the margins such as indigenous women and men, displaced urban poor and rural communities. In the late 1990s/early 2000s working with Escobar, Kothari and others we published a series of studies in the journal on women and the politics of place that looked at women's defense of their homes, environment and livelihoods as well as women's organizing and creative resistance for personal and community survival.

The Development journal traces in its articles and special issues an intertwining of post-development and transformative practices in gender and development. For me 
this joint venture in the search for living otherwise points to important ways forward as we look at how to live economic and social practices based on care for others and the environment.

\section{Sustainable Development}

The recognition of the violence of development is starkly evident in the increasingly unsustainability of dominant economic and social 'life-worlds'. There are many contradictions and difficulties of bringing environmental concerns in development and gender discourses, beginning with the need to unpack western science and economic ideological assumptions on which development is based. There are many fears that we need to look at unflinchingly, given the endgame we are playing with the Earth's resources.

Respect for the environment and limitations to extractive development has been central to the Development journal since the 1980s. Many articles and special issues have focused on the importance of environment with key ecological activists and scholars writing in its pages. Particularly important has been how gender has been brought together with environment through the writings of well-known ecofeminists such as Vandana Shiva and Wangari Matthai as well as feminist political ecologist such as Dianne Rocheleau and my own writing. These points of view have complimented and enriched the debates in the journal pages joined by political ecologists Wolfgang Sachs, Smitu Kothari, Arturo Escobar, Ashish Nandy and many others writing on sustainable livelihoods and alternatives to development. This community of writers and advocates are deeply concerned that development has led to the displacement of communities, the scarring of landscapes, the violation of bodies and the destruction of traditional agricultures. In their studies, gender power relations are explored in the changing economic and social 'life-worlds' or the intertwining of all living beings.

These articles and discussions in SID events, have set out how local people live, feel and understand the environment looking at practices of care and well-being that make up community economic and ecological negotiations around the management of shared resources. They pay attention to the importance of community responses to climate, economic and environmental change from a gendered perspective.

In its coverage of community change, gender and environment the journal also published studies advocates and writers also looked critically at the relations between gender, environment and development with articles about the global negotiations in the decades following the UN Conference on Environment and Development (UNCED) held in September 1992 in Rio de Janeiro. In articles in the journal (including my own) the behind the scenes politics of the insider knowledge and negotiations in the government and UN arena traced the gendered processes of negotiation around development.

A gender approach to sustainable development beings by working with communities in economically marginal communities considering ecological, technological and 
political-economic processes in order to address the inequalities and gender biases informing resource transformations due to anthropogenic climate change.

A gender analysis of global environment and development is key to ways to tackle the growing crises of climate, food insecurity, economic inequalities as well as increasing conflict and prejudice. Understanding gender power relations in environmental and development negotiations is important in order to consider community responses to the current climate economic and environmental crises in multiple places. In the future we need to continue to learn from how different peoples see and understand the world in ways that can mitigate the starkly divergent interests of different world communities. It is these stories that will enable us to promote ways for new political, economic and community innovations to emerge.

\section{Conclusion}

While not being able to do justice to all the themes that have been discussed and debated around gender and development in the pages of the Development journal over the last 60 years, in this article, I have traced four themes which I see as salient for the future, and which illustrate from the past the crucial importance of gendered processes in development. Diversity, body politics, post-development and sustainable development continue to be at the basis of the gender and development agenda.

Learning from the doing of gender and development we can shape a future development agenda that is transformative at the deepest levels. Such a (post) development framework would be based on women's rights and gender equality as well as the elimination of all forms of racialized and gender-based discrimination, including sexual and gender-based violence against lesbian, bisexual and transgender people. Such an agenda would address the gender biases and inequalities in both the formal and care economy and seek to establish comprehensive sexual and reproductive health and rights as part of the broader goal of achieving political, economic, social and ecological justice.

\section{References}

Barton, Carol. 2006. Integrating Feminist Agendas: Gender justice and economic justice, in Sexual and Reproductive Health and Rights, Development 48(4): 75-84.

Belausteguigoitia Rius, Marisa. 2012. Indigenous Women and the Land: Shifting language, action and culture, in Cosmovisions, Development 54(4): 433-436.

Cornwall, Andrea and NanaAkua Anyidoho. 2011. Introduction: Women's Empowerment: Contentions and Contestations, in Gender and Empowerment, Development 53(2): 144-149.

Grown, Caren. 2005. Answering the Skeptics: Achieving gender equality and the Millennium Development Goals, in Peacebuilding Through Justice, Development 48(3): 82-86.

Harcourt, Wendy. 2010. Development as if Gender Matters, in Gender and Empowerment, Development 53(2): 210-214.

Lind, Amy. 2010. Governing Intimacy, Struggling for Sexual Rights: Challenging heteronormativity in the global development industry, Sexuality and Development, Development 52(1): 34-42. 
Nayar, Anita. 2009. Women's Rights in a Changing World, in Women's Rights and Development, Development 49(1): 46-48.

Sen, Gita. 2013. Surviving the Fierce New World, in Gender and Economic Justice, Development 55(3): 266-268.

Tamale, Sylvia. 2009. African Feminism, in Women's Rights and Development, Development 49(1): 3841.

Wichterich, Christa. 2014. Occupy Development - Towards a Caring Economy, The Future of Global Governance, Development 56(3): 346-349. 